\title{
AMENDMENTS
}

\section{Author Correction: Systematic review of the outcomes and trade-offs of ten types of decarbonization policy instruments}

\author{
Cristina Peñasco (D), Laura Díaz Anadón (iD) and Elena Verdolini (iD
}

Correction to: Nature Climate Change https://doi.org/10.1038/s41558-020-00971-x, published online 18 January 2021.

In the version of this Analysis originally published online, in the third sentence of the Data availability section, the link 'https://pet. innopahts.eu/' was incorrect; it should have been 'http://dpet.innopaths.eu/\#/'. All versions of the Analysis have been corrected.

Published online: 9 February 2021

https://doi.org/10.1038/s41558-021-00992-0

๑ The Author(s), under exclusive licence to Springer Nature Limited 2021

\section{Publisher Correction: Achievements and needs for the climate change scenario framework}

Brian C. O'Neill (D), Timothy R. Carter (D), Kristie Ebi (D), Paula A. Harrison (D), Eric Kemp-Benedict (D), Kasper Kok, Elmar Kriegler (D), Benjamin L. Preston, Keywan Riahi, Jana Sillmann (D), Bas J. van Ruijven (D), Detlef van Vuuren (D), David Carlisle, Cecilia Conde, Jan Fuglestvedt D, Carole Green, Tomoko Hasegawa (D), Julia Leininger, Seth Monteith and Ramon Pichs-Madruga

Correction to: Nature Climate Change https://doi.org/10.1038/s41558-020-00952-0, published online 25 November 2020.

In the version of this Perspective originally published, the footnote of Table 1 incorrectly described the meanings of symbols in the table, and the tick marks paired with obeli symbols should have been + signs. The symbols have been amended, as has the footnote, which now reads "Tick marks indicate recommendations made to address the issue in the indicated column; + signs indicate benefits to additional issues". The online versions of the Perspective have been corrected.

Published online: 20 January 2021

https://doi.org/10.1038/s41558-020-00981-9

(c) The Author(s), under exclusive licence to Springer Nature Limited 2021

\section{Publisher Correction: Soil moisture-atmosphere feedbacks mitigate declining water availability in drylands}

Sha Zhou (D), A. Park Williams, Benjamin R. Lintner, Alexis M. Berg DD, Yao Zhang (D), Trevor F. Keenan, Benjamin I. Cook, Stefan Hagemann, Sonia I. Seneviratne (D) and Pierre Gentine (D)

Correction to: Nature Climate Change https://doi.org/10.1038/s41558-020-00945-z, published online 4 January 2021.

In the version of this Article originally published, the multiplication symbol was mistakenly used instead of the dot product in equations (1) and (4)-(11). This has now been corrected in the online versions of the Article.

Published online: 20 January 2021

https://doi.org/10.1038/s41558-021-00988-w

(c) The Author(s), under exclusive licence to Springer Nature Limited 2021 